\title{
Discovery and basic pharmacology of erythropoiesis-stimulating agents (ESAs), including the hyperglycosylated ESA, darbepoetin alfa: an update of the rationale and clinical impact
}

\author{
Zoltán Kiss • Steven Elliott • Kinga Jedynasty • \\ Vladimír Tesar • János Szegedi
}

Received: 25 September 2009 / Accepted: 18 December 2009/Published online: 2 February 2010

(C) Springer-Verlag 2010

\begin{abstract}
Cloning of the human erythropoietin $(E P O)$ gene and development of the first recombinant human erythropoietin (rHuEPO) drug were truly breakthroughs. This allowed a deeper understanding of the structure and pharmacology of rHuEpo, which in turn inspired the discovery and development of additional erythropoiesisstimulating agents (ESAs). In vivo specific activity and serum half-life of rHuEPO are influenced by the amount and structure of the attached carbohydrate. Increased numbers of sialic acids on carbohydrate attached to rHuEPO correlated with a relative increase in in-vivospecific activity and increased serum half-life. The effect of increasing the number of sialic-acid-containing carbohydrates on in-vivo-specific activity was explored. Initial research focused on solving the problem of how the protein
\end{abstract}

\author{
Z. Kiss $(\bowtie)$ \\ Amgen Kft., \\ Budapest, Hungary \\ e-mail: zkiss@amgen.com \\ S. Elliott \\ Amgen Inc., \\ Thousand Oaks, CA, USA \\ K. Jedynasty \\ Amgen Gmbh., \\ Wien, Austria \\ V. Tesar \\ Department of Nephrology, 1st School of Medicine and \\ University Hospital, Charles University, \\ Prague, Czech Republic \\ J. Szegedi \\ Local Government of Szabolcs-Szatmár-Bereg County, \\ Jósa András Instructional Hospital, Internal Medicine I., \\ Nyíregyháza, Hungary
}

backbone could be engineered so a cell would add more carbohydrate to it. Additional work resulted in darbepoetin alfa, a longer-acting molecule with two additional carbohydrate chains.

Keywords Red blood cell (RBC) - Biological activity . Erythropoietin (EPO) - Erythropoiesis-stimulating agent (ESA) - Recombinant human erythropoietin (rHuEpo) . Carbohydrate $\cdot$ Sialic acid $\cdot$ Darbepoetin alfa .

Glycoengineering $\cdot$ Biosimilar $\cdot$ FOB

\section{Introduction}

Red blood cells (RBCs) represent $>99 \%$ of total circulating blood cells $\left(\sim 5 \times 10^{12}\right.$ per liter, or $2.5 \times 10^{13}$ total $)$ and typically occupy approximately $40-45 \%$ of the total blood volume. Hemoglobin $(\mathrm{Hb})$, the predominant molecule that transports oxygen $\left(\mathrm{O}_{2}\right)$ from the lungs to tissues, constitutes $99 \%$ of the cytosolic protein in mature RBCs [1]. This large amount of $\mathrm{Hb}$ is consistent with the requirement for a large $\mathrm{O}_{2}$ transport capacity that must support the considerable consumption of $\mathrm{O}_{2}$ in tissues. The lifespan of an $\mathrm{RBC}$ is approximately $100-120$ days, indicating that $\sim 1 \%$ of the total must be replaced each day. Replacing this number of cells requires a prodigious $\mathrm{RBC}$ production rate. This means creation of $>10^{10}$ new RBCs per hour, which exactly matches the rate of RBCs disappearance. Should the loss of RBCs exceed their production, anemia can occur.

Prior to the discovery of recombinant human erythropoietin (rHuEPO), anemic patients with chronic kidney disease were treated with $\mathrm{RBC}$ transfusions with all its disadvantages. The major clinical benefits of rHuEPO were treatment of anemia and avoidance or minimization of 
blood transfusion and its associated risks. rHuEPO is administered by injection three times a week, which aligns well for dialysis patients receiving thrice weekly treatments; however, for chronic kidney disease (CKD) patients not on dialysis, this dosing schedule may introduce hardship, as patients often need to visit the clinic solely for the purpose of erythropoiesis-stimulating agent (ESA) administration. Prolonging the dosing interval for ESAs could be addressed by an increase in dose. Another possibility was to create a new rHuEpo glycosylation analog that had a longer serum half-life [2]. Research into this possibility resulted in the discovery of a novel ESA, Aranesp ${ }^{\circledR}$ (darbepoetin alfa), which became available for anemic patients at the start of this decade. The aim of this paper is to summarize the discovery and development of recombinant rHuEPO and present the characteristics of ESAs and results of current ESA research, particularly focusing on darbepoetin alfa.

\section{Erythropoietin and erythropoiesis}

Details on the early history of erythropoietin and erythropoiesis, including the discovery of darbepoetin alfa and its properties, has been described in earlier work [2-5]. Therefore, this paper describes the similarities and differences in the various ESAs, as well as their functional properties, with a focus on darbepoetin alfa. It was not until the 1980s that researchers from Amgen (led by Lin) isolated the human EPO gene [6]. Cloning the EPO gene was a breakthrough in treatment of anemia. Endogenous and recombinant erythropoietin both consist of a single polypeptide chain backbone [7] composed of 165 amino acids (Fig. 1). The structure of rHuEPO is a compact globular bundle, which contains four alfa helices [8].

Endogenous EPO production in adult humans occurs primarily in interstitial kidney cells. However EPO can also be produced in smaller amounts in the liver. Recent reports suggest EPO may also be expressed by cells of the central nervous system. Whereas reports of EPO expression elsewhere have been suggested, the reagents and methodologies associated with this work are of insufficient sensitivity and specificity to draw valid conclusions. Hypoxia results in increased EPO gene transcription through an increase in amount of a hypoxia -inducible factor (HIF) [9]. HIF binds to a hypoxia-responsive element located adjacent to the coding region of the EPO gene, resulting in increased gene transcription. As a consequence of tissue hypoxia, the EPO concentration in serum can increase up to $100-1,000$-fold. Following synthesis of the protein portion of the molecule, posttranslational carbohydrate addition (glycosylation) can occur and in mammalian cells, there is further maturation into complex carbohydrates. Endogenous EPO and rHuEPO (such as epoetin alfa) contain three specific N-linked glycosylation sites (Asn24, Asn38, and Asn83) and one O-linked glycosylation site (Ser126). rHuEPO has four carbohydrate chains attached to these sites representing approximately $40 \%$ of total hormone mass [10].

The correctly folded erythropoietin molecule has two erythropoietin-receptor-binding sites with high and low affinities [11]. EPOR (erythropoietin receptor), which is found on the surface of erythroid precursor cells, is a cell-
Fig. 1 Amino acid sequence of human erythropoietin (EPO) with glycosylation at three specific asparagines residues (Asn24, Asn34, and Asn83) and one serine residue (Ser126) [3]
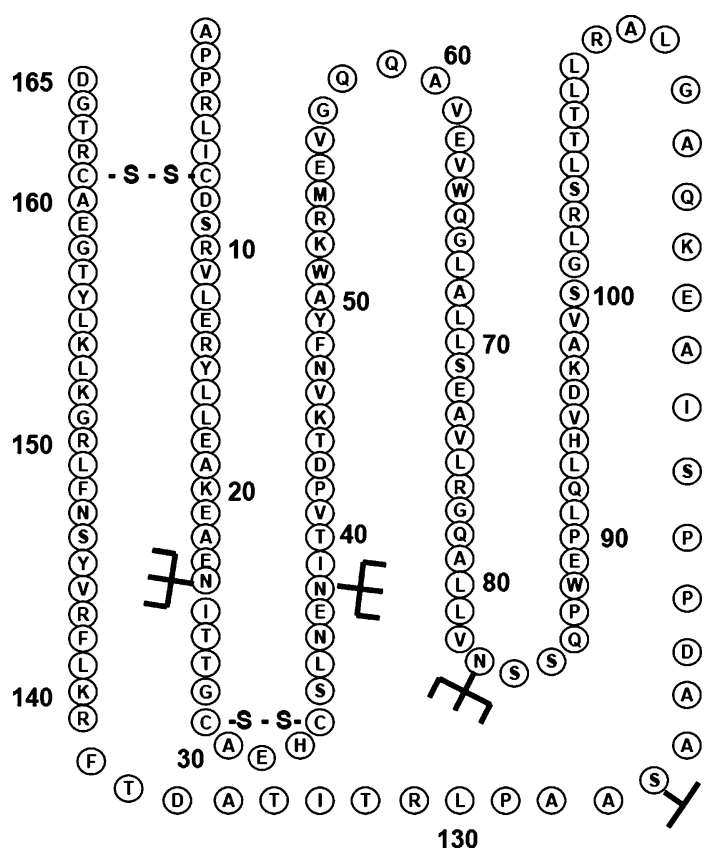

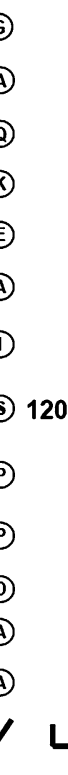


membrane-bound protein that is activated when one EPO molecule binds to two receptors in a process called homodimerization $[8,11,12]$. When EPO receptors on erythroid precursor cells are activated by EPO, the cells can be stimulated to survive, proliferate, and differentiate into RBCs.

Under certain conditions, such as when individuals descended from high altitude, the RBC mass decreased by approximately $10-15 \%$ over $7-10$ days. This fact led to the proposal that EPO regulated not only production of RBCs but also their survival through an EPO-dependent physiologic down-regulation of RBC mass called neocytolysis [13]. However, RBCs lack EPO receptors, suggesting the mechanism by which RBC number declined must be indirect. One possibility was that RBCs were eliminated from the circulation with the help of the reticuloendothelial system (RES) involving EPO receptors on vascular endothelium or on phagocytes. Endothelial cells were recently shown to have undetectable levels of functional EPOR [14], raising questions about this mechanism. A more likely possibility is that RBC lifespan is impacted by oxidative damage that is increased when individuals with reticulocytosis due to adaptation to high altitude descend to lower altitude where increased oxygen could result in increased RBC destruction. Consistent with this proposal, rats exposed to hyperoxia had increased destruction of RBCs [15], as did human astronauts exposed to hyperoxia in space flight $[16,17]$. A mechanism by which oxidative damage may be regulated has recently been described. Forkhead box $\mathrm{O} 3$ (FOXO3a) is expressed during erythroid differentiation and reportedly plays an important role in $\mathrm{RBC}$ survival by inducing antioxidative proteins such as catalase, superoxide dismutase, growth arrest, and DNA damage-inducible 45 (GADD45) $[18,19]$. Because expression of FOXO3a, and by necessity, its downstream targets, require nuclear DNA, RBCs that have no nucleus become dependent on the antioxidative proteins made earlier.

\section{Nonhematopoietic effects of erythropoietin}

Recent results on possible nonerythropoietic effects of ESAs drew the attention of the scientific community. The possibility was supported by genetic studies in which EPO and EPOR knock-out mice presented with abnormal brain, cardiac, and blood-vessel development, suggesting that EPO and its receptor was involved in normal organ development [20]. In other studies, ESA administration reduced the magnitude of ischemic lesions in the nervous system, myocardium, and kidney [21]. For example, darbepoetin alfa reportedly had a protective effect on podocytes and reduced apoptosis in the kidney [22]. In rats with puromycin-induced nephrotic syndrome, darbepoetin alfa administration could reduce proteinuria [23]. In addition, ESAs were reported to induce signaling in cell lines made quiescent by serum starvation [24]. The notion was extended to include Epo receptors on endothelial and tumor cells and that addition of ESAs to patients might stimulate tumor growth [24]. The proposed mechanism was that EPO bound to EPO receptors expressed on nonhematopoietic and tumor cells, resulting in growth promotion and/or an antiapoptotic effect. However, we should be caution with this theory. In tumor rodent xenograft studies, there was no increased growth in the ESA arm [25]. In addition, the clinical trial results were controversial because of baseline imbalances in some of the trials that favored the placebo arm [26].

The notion that EPO receptors were expressed on nonhematopoietic and tumor cells was based largely on Western immunoblotting or immunohistochemistry experiments using antibodies that were shown to be nonspecific [27, 28]. In addition, there are other results inconsistent with the hypothesis. Mice that were engineered to express EPOR exclusively in hematopoietic cells showed normal size and development, with no effect on development of the vascular endothelium [29]. In experiments designed to detect EPOR-induced signaling in tumor cell lines, including those reported to respond to ESAs by others, no effect was detected [30]. More recently, a specific antibody to human EPOR was described [31], and its application to EPOR expression in nonhematopoietic cells from kidney and heart tissues and endothelium revealed low to undetectable levels of EPOR protein. In these same cell types, no detectable EPO induced signaling, and no consistent antiapoptotic effect of ESAs with in vitro cell cultures was observed [14]. In a study with $>200$ tumor cell lines, EPOR was detected in only a subset of the total, and many of the lines with undetectable EPOR protein included cell lines reported by others to respond to EPOR [32]. In the tumor cell lines expressing the highest relative levels of EPOR, there was no detectable induction of Epo-induced signaling and no effect on cell viability detected due to knock-down of EPOR by transfection with EPOR small interfering RNA (siRNAs). A direct examination of tumor cell response to EPOR was also undertaken. In $>150$ live tumors from patient biopsies, no ESA-induced signaling was detected in disaggregated cells, whereas robust responses were readily detected in the same cells treated with a positivecontrol growth-factor cocktail [33].

It is not possible to completely reconcile all the reported results, suggesting other mechanisms may be at play. One possibility is that the increased iron metabolism needed to support ESA-induced erythropoiesis may reduce oxidative stress [34]. Alternatively, increases in oxygen delivery at elevated hematocrits or changes in heart rate or blood 
hemodynamics may also explain the benefit of ESAs in certain animal studies. Clearly, further research is required to define the precise mechanism.

\section{rHuEPO and follow-on biologics/biosimilars}

Endogenous EPO is a complex biological produced by specialized cells that are impacted by forces unique to the body, including a complex interaction of circulating growth factors, nutrients, and particular cell-cell interactions. Circulating Epo is then subject to differential clearance of the various glycoforms. It is not possible to duplicate these processes in a manufacturing setting, thus rHuEPO differs from endogenous EPO. These differences include posttranslational modifications as well as the type and amount of contaminants, such as fragments and aggregated forms. Changes in cell lines or even more changes in growth conditions or manufacturing processes can affect the final ESA product characteristics, including the microheterogeneity of glycoforms. Changes in glycosylation can impact functional activities, such as binding affinity for cognate ligands, signal transduction, cellular internalization, and resistance to proteolytic degradation; and physical properties such as stability and solubility. These can affect product quality as well as clearance, efficacy, and safety.

It is not possible for another manufacturer to match exactly the cell line or the manufacturing conditions and consequently the product profile of the innovator product. Therefore, rHuEPO ... products made by different manufacturers are not identical to each other. Because of these differences, the term "generic" is not used to describe rHuEpo molecules made by different manufacturers. Instead, the descriptors "follow-on biologics" (FOBs) in United States, and "biosimilars" in European Union are used [35]. Epoetin alfa was the first commercialized rHuEPO (Epogen ${ }^{\circledR}$, Procrit ${ }^{\circledR}$, Eprex ${ }^{\circledR}$ ) and used Chinese hamster ovary $(\mathrm{CHO})$ cells in its manufacture. Other epoetins (biosimilars) followed with different Greek names, reflecting the different cell lines and manufacturing methods (Table 1). The second approved rHuEPO was epoetin beta (Recormon ${ }^{\circledR}$, Neorecormon ${ }^{\circledR}$ ) and also used $\mathrm{CHO}$ cells in its manufacture. It, like other rHuEpo biosimilars, has the same amino acid sequence as epoetin alfa with some minor differences in the microheterogeneity in the attached carbohydrate. Epoetin delta used human fibrosarcoma (HT1080) cells in its manufacture, but as of December 2008 is no longer distributed. Epoetin omega, produced in baby hamster kidney cells (BHK), differed somewhat from epoetin alfa and beta in the glycosylation profile. Other ESA biosimilars are being introduced in the EU, such as epoetin zeta. However, there are inconsistencies in the

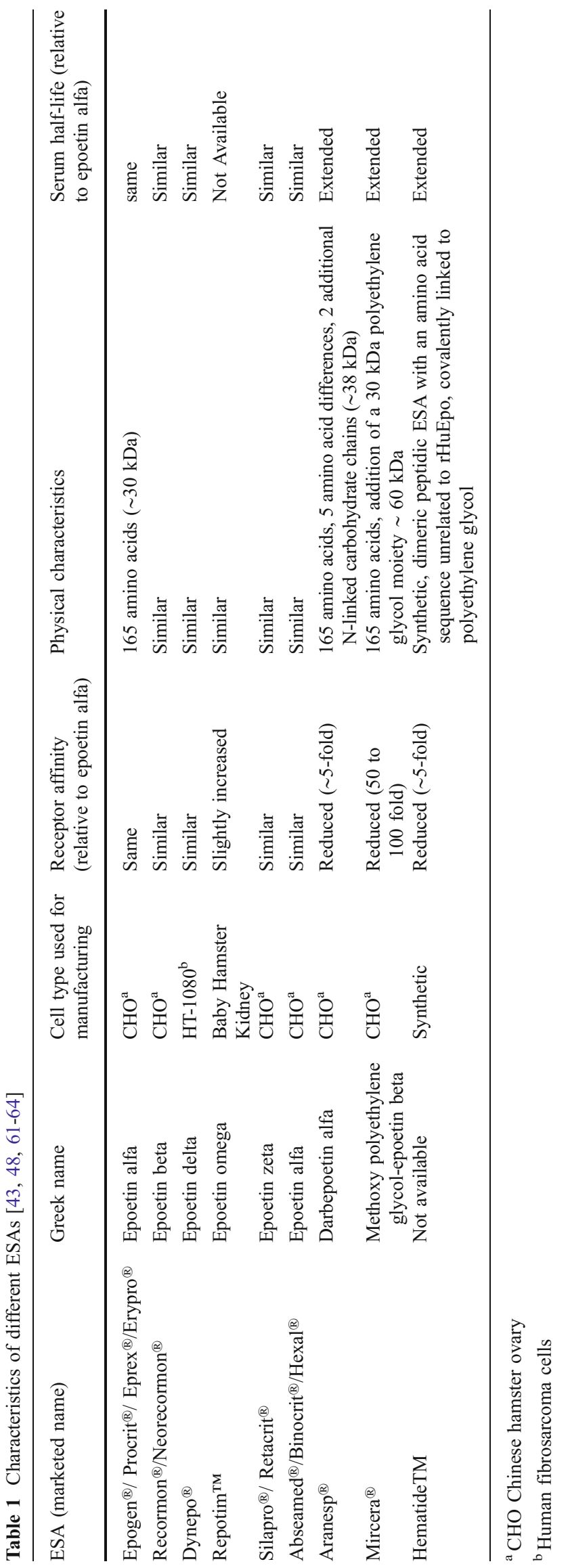


naming convention, such as with Abseamed/Binacrit/Hexal, which is marketed as an epoetin alfa.

rHuEPO FOBs are also manufactured and distributed in countries where less oversight on drug manufacturing results in significant product quality and structural differences from epoetins distributed in the USA and EU [36-38]. These ESAs can vary considerably from each other and from marketed epoetins manufactured in the USA and EU in labeling, drug content, and specific activity. Even though different ESAs can share the same Greek name, there may also be considerable lot-to-lot variability. There have been reports that some patients administered these ESAs have presented with antibody-mediated pure red cell aplasia. Because a patient's safety is always the first and foremost aspect in treatment, switching patients from one rHuEPO to another should be performed by skilled health care practitioners who take into account both long-term efficacy and safety issues.

\section{Role of carbohydrate on EPO activity}

The biological effect of EPO (stimulation of erythropoiesis) is controlled by the interaction of EPO with its receptor. This interaction involves direct contact of the protein portion of EPO with the protein portion of the EPO receptor. The affinity of EPO to EPOR (the concentration of EPO required for half-maximal binding) can affect the magnitude of binding and therefore magnitude of response at a given EPO concentration. However, other elements of EPO also affect the biophysical properties as well as the magnitude of the biological response. Attached carbohydrate on rHuEpo comprises approximately $40 \%$ of the mass of the molecule [7]. Whereas differences in carbohydrate content of EPO can affect affinity to EPOR, carbohydrate also plays an important role in maintaining the molecule in circulation (clearance) [39]. In addition to its effect on clearance, the increased content of negatively charged carbohydrates can also increase solubility and decrease adhesive properties of protein. Thus, the carbohydrate may shield hydrophobic residues, reducing aggregation while protecting potential immunogenic surfaces from immune surveillance.

Carbohydrate made in mammalian cells and attached to proteins is composed of a mix of various sugar molecules joined together into complex chains. Individual chains on rHuEPO can differ from others in sugar content, size, and degree of branching. One of the sugars found on the ends of each branch of a carbohydrate chain is a negatively charged molecule, sialic acid. Because of the microheterogeneity in number of branches, EPO has a natural variation in charge due to variation in sialic acid content. The presence of up to four negatively charged sialic acids on each of the three N-linked carbohydrate chains and up to two sialic acids on the single O-linked carbohydrate chain results in up to 14 sialic acids on both endogenous and rHuEPO [2]. Endogenous EPO is differentiated from $\mathrm{rHuEPO}$ in that there is further charge modification due to addition of sulfate to the carbohydrate. About $3 \%$ of the carbohydrate chains on epoetin alfa contain sulfate, and the content is typically limited to one sulfate per chain. In contrast, endogenous EPO can be extensively sulfated, with as many as three sulfates per carbohydrate chain. Thus, endogenous EPO can be considerably more negative (acidic) than rHuEpo [40-42].

A research group [42] performed studies on purified fractions of rHuEPO that had defined numbers of sialic acids and observed a positive correlation between sialic acid content of rHuEPO and in-vivo-specific activity. There was a similar positive correlation between sialic acid content and serum half-life for those isoforms. On the other hand, molecules with increased sialic acid content had less affinity to EPOR [42] (Fig. 2). These results indicate that in the case of rHuEPO, a longer half-life is a stronger determinant of in-vivo-specific activity than affinity to EPOR. However, from the clinical point of view, a balanced proportion of these two parameters is important.

$\mathrm{N}$-linked carbohydrate attachment points consist of welldefined three amino acid consensus sequences (Asn-XxxSer/Thr), where Xxx could be any amino acid except proline $[43,44]$. In order to add additional carbohydrate chains to rHuEPO, the coding region of the $E P O$ gene was altered so that new N-linked consensus sequences were present and that a cell expressing these modified genes

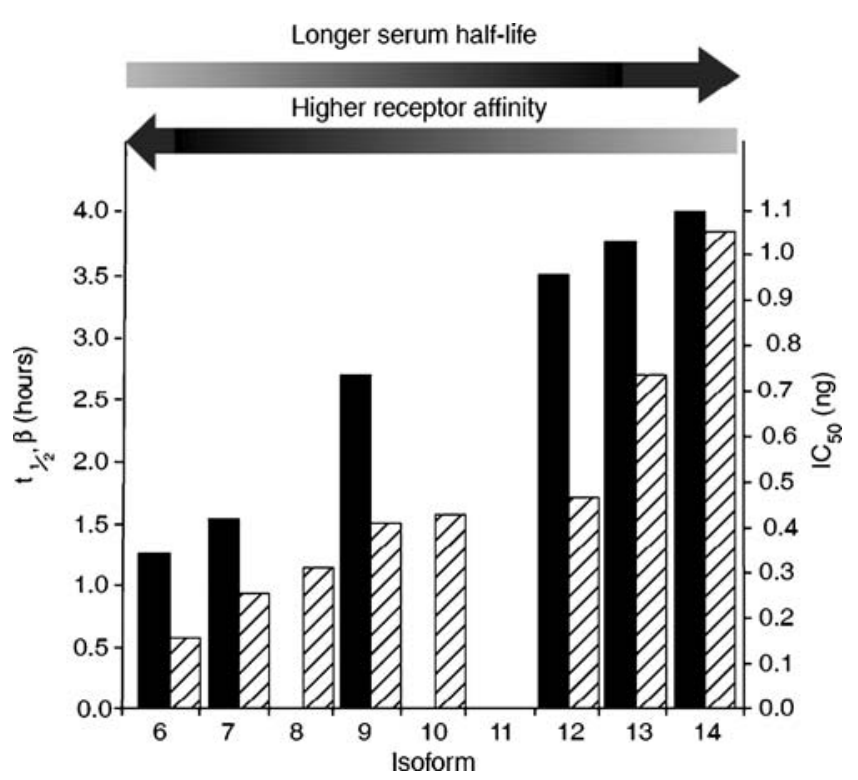

Fig. 2 Serum clearance is the primary determinant of in vivo activity of erythropoietin isoform (from [42], with permission) 
would recognize the new carbohydrate attachment points in $\mathrm{rHuEPO}$. Using in vitro mutagenesis, rHuEPO glycosylation analogs with varying numbers of N-linked carbohydrate chains were successfully constructed and became available for testing [11, 39]. Addition of one new carbohydrate chain increased approximately 1.6 -fold the in-vivo-specific activity in rodents, and addition of two chains resulted in greater than twofold increase, as measured by the exhypoxic polycythemic mouse bioassay [39]. In contrast, when one N-linked chain was removed from the protein backbone of rHuEPO, the in-vivo-specific activity decreased approximately two- to fourfold. Removal of two chains resulted in about a 50-fold decrease. Overall, there was a general, positive correlation between number of carbohydrate chains and in-vivo-specific activity [39] (Fig. 3). Whereas the position of the attached sugar chain also affected the in-vivo-specific activity, the number of chains played the more important role.

The effect of number of carbohydrate chains on EPO receptor binding activity was also examined. Unglycosylated $\mathrm{rHuEPO}$, prepared by expression in Escherichia coli, had approximately sevenfold higher EPO receptor binding activity than did glycosylated rHuEPO. In contrast, as the number of N-linked carbohydrates increased, the receptor-binding activity decreased in a loglinear relationship [39]. The glycosylation analog with one additional N-linked carbohydrate (four in total) had a threefold reduced binding activity. Darbepoetin alfa, having two more $\mathrm{N}$-linked carbohydrates than rHuEPO, had a binding activity approximately fivefold lower. N53, an analog with three additional carbohydrates compared with rHuEPO, had a 20 -fold decrease. Thus, the positive relationship between carbohydrate number and in vivo activity could not be explained by increases in EPO receptor-binding activity.

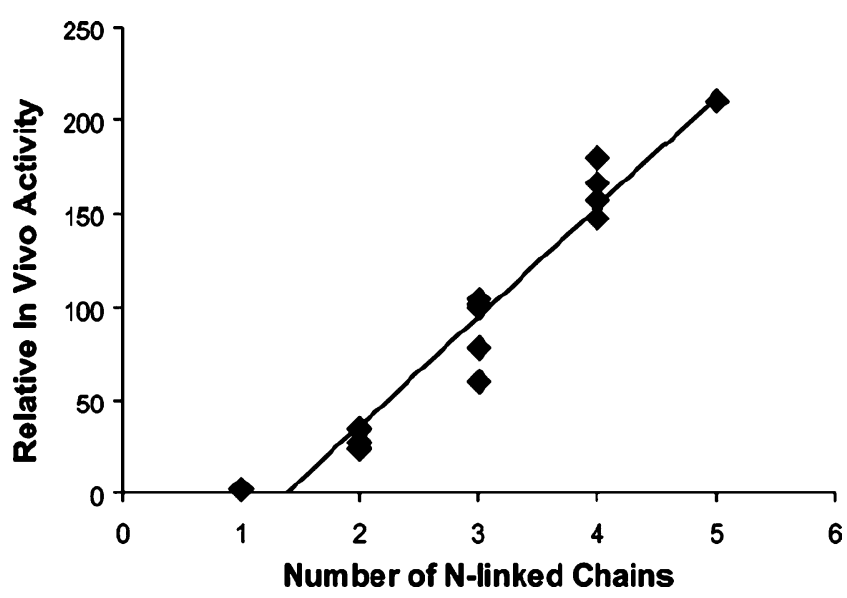

Fig. 3 In vivo activity of erythropoietin (EPO) glycosylation analogs increases with increasing number of $\mathrm{N}$-linked carbohydrate chains ([from 39], with permission)

\section{Successful development of darbepoetin alfa}

The novel erythropoiesis-stimulating protein darbepoetin alfa (Aranesp ${ }^{\circledR}$ ) contains two additional N-linked carbohydrate chains at positions 30 and 88 as a result of five aminoacid substitutions (Ala30/Asn, His32/Thr, Pro87/Val, Trp88/Asn, Pro90/Thr) in the protein backbone [45] (Fig. 4 and Table 1). The new sites were introduced at positions that did not directly interfere with the Epo:EpoR interaction or disrupt the structure or stability of the molecule. Because of the two additional N-linked carbohydrate chains, the molecular weight increased from 30 to $37 \mathrm{kDa}$ and the carbohydrate part of the new molecule increased from $40 \%$ to $51 \%$. Importantly, the maximum number of sialic-acid residues increased from 14 to 22 , resulting in an increase in serum half-life [46]. Molecules with carbohydrate contents greater than darbepoetin alfa (N53 and AMG114) and polyethylene glycol-linked darbepoetin alfa (peg-Aranesp) have also been examined, and these have a further increase in serum half-life. However, the pharmacokinetic and pharmacodynamic properties of darbepoetin alfa are appropriate for current clinical practice, indicated for administration up to once per month in certain countries, and it maintained stable $\mathrm{Hb}$ levels in anemic patients.
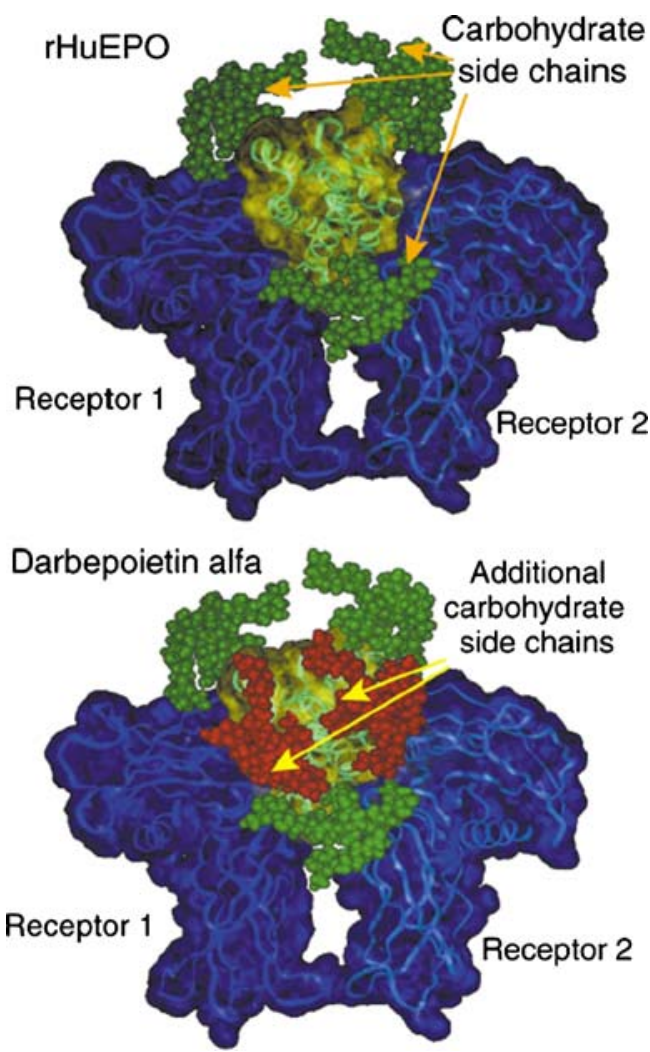

Fig. 4 Molecular comparison of recombinant human erythropoietin (rHuEPO) and darbepoetin alfa, which have the same mechanism of action (from [45], with permission) 
In the research and development of a new ESA suitable for clinical use, there are many factors to be considered, including a reasonable balance between serum half-life and affinity to the EPO receptor. Another concern is that a serum half-life that is too long may result in loss of $\mathrm{Hb}$ control due to the extended time the agent can stimulate erythropoiesis. Therefore, there may be an optimal range of association of these parameters where the balance between receptor affinity, half-life, dose, and dosing interval is a beneficial one. In comparison with $\mathrm{rHuEPO}$, darbepoetin alfa had a threefold longer serum half-life in animals [47] and humans [48-50]. In patients on peritoneal dialysis, the terminal half-life of darbepoetin alfa after intravenous administration in patients was approximately $25 \mathrm{~h}$, and following subcutaneous administration, the half-life was approximately $49 \mathrm{~h}$ [50, 51] (Fig. 5.) However, in peritoneal dialysis and in predialysis patients after a single subcutaneous administration, the mean terminal half-life of darbepoetin alfa was between 65 and $105 \mathrm{~h}$ [50]. The apparent terminal half-life of darbepoetin alfa was twofold longer with the subcutaneous compared with intravenous route of administration. The dose requirement in order to maintain similar hemoglobin serum levels in patients with anemia was similar with the two routes of administration, indicating there was no loss of efficiency [52]. The similar dose requirement is explained by the longer half-life associated with subcutaneous route resulting in longer exposure of the drug, which compensates for the reduced subcutaneous bioavailability $(\sim 37 \%)$.

Darbepoetin alfa has a fivefold decreased receptorbinding-specific activity compared with rHuEPO [39, 47]. Therefore, the minimal effective concentration (MEC), or in other words, erythropoiesis threshold, is higher with darbepoetin alfa compared with rHuEPO. This suggests that higher serum concentrations of darbepoetin alfa may be required to get similar fractions of ESA-bound receptors, which theoretically could result in reduced in-vivo-specific

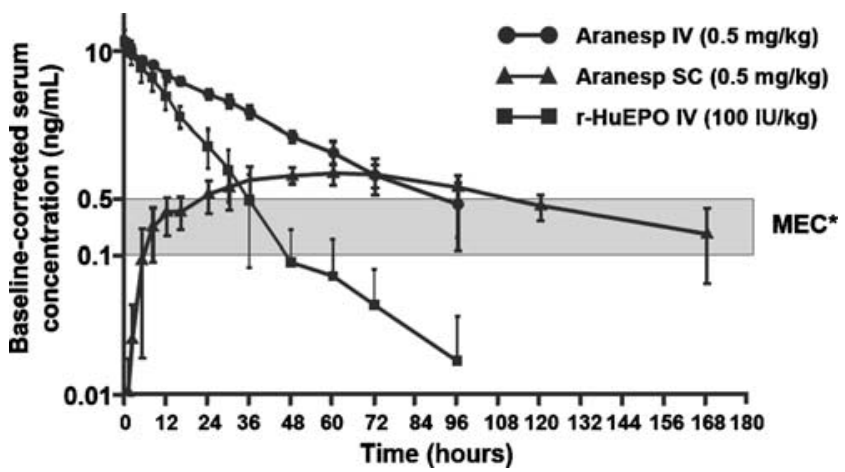

Fig. 5 Darbepoetin alfa serum concentration in stable peritoneal dialysis patients remains above the minimal effective concentration (MEC) for erythropoiesis longer than an equivalent dose of recombinant human erythropoietin (rHuEPO) (from [51], with permission) activity or efficacy. However, the additional carbohydrate on darbepoetin did not blunt the biological response [53], and the same signal transduction pathways were stimulated with similar kinetics and magnitude $[39,53]$. When in vitro and in vivo activities were compared, the shapes of the dose-response curve, maximal stimulation, and hematological response were all similar, suggesting that the different carbohydrate content can affect the specific activity but did not affect function per se.

Darbepoetin alfa actually has increased in-vivo-specific activity compared with rHuEPO despite its reduced receptor-binding-specific activity. In a multicycle carboplatin chemotherapy/radiotherapy model in mice [54], a sixfold higher dose of rHuEPO was required to match the effect of the lower dose of darbepoetin alfa. In normal mice, in order to maintain or elicit a similar erythropoietic response, three times more rHuEPO was needed than darbepoetin alfa to provide the same response at three times per week administration in mice [47, 55] (Fig. 6). When the dosing interval was extended to weekly administration, the difference increased to 13 -fold. With a single injection, the dose of rHuEPO needed to be 30-40 times higher to match the effect of the lower dose of darbepoetin alfa. This and the relative in-vivo-specific activity of darbepoetin alfa compared with rHuEPO increased with increasing dosing interval. Increased specific activity of darbepoetin alfa compared with rHuEPO was also reported in human clinical studies [56]. In humans administered darbepoetin alfa with a Q2W (every other week) dosing regimen, the same total dosage could successfully maintain $\mathrm{Hb}$ levels in renal anemic dialysis patients in comparison with QW (weekly) administration of the drug [57]. Similarly, in the predialysis population, QM (monthly) administration of the drug maintained $\mathrm{Hb}$ concentration at the same total dose in comparison with Q2W administration [58]. However it is not clear whether a relative increase in dose is required for monthly administration in dialysis or other patients.

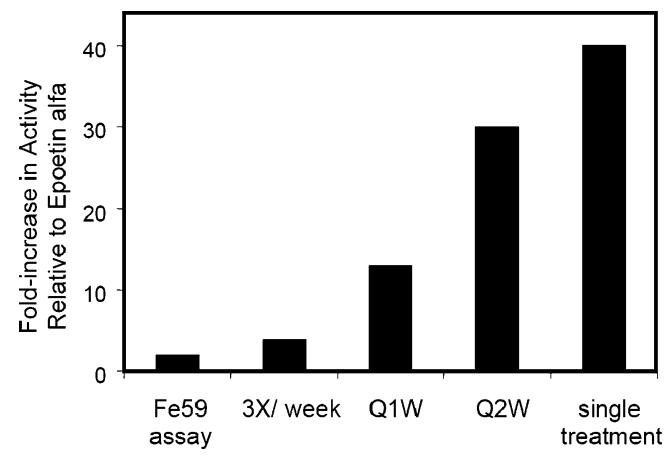

Fig. 6 In vivo activity of darbepoetin alfa increases compared with recombinant human erythropoietin (rHuEPO) as dose interval increases in mice $[47,55]$ 
The apparent paradox, that rHuEPO glycosylation analogs with reduced receptor-binding-specific activity had increased in vivo specific activity, is explained by the counteracting effects of sialic-acid-containing carbohydrate on clearance. Slower clearance in vivo results in a slower decline in serum concentration over time when slow and faster clearing molecules are compared, and the relative concentration differences will increase with time. In addition, the ESA doses typically used clinically are sufficiently high to ensure sufficient numbers of EPO receptors are bound for effective erythropoiesis. As a result, the prolonged drug exposure more than compensates for the reduced receptor-binding-specific activity [39] (Fig. 7a) and can result in increased in-vivo-specific activity.

In practice, half life and binding affinity to the EPOR can move independently from each other. Therefore, a longer half-life may not necessarily result in increased specific bioactivity. For example, a drug with sixfold longer half-life may not show increased specific activity if the affinity to the receptor was substantially lower, e.g., 50-fold (Fig. 7b). This would be especially true if the starting concentration was not high enough to ensure that sufficient EPO receptors were bound following ESA administration. An additional issue with agents that have substantially prolonged serum half lives is that an overshoot in Hb levels may occur because of the prolonged time that erythropoi-
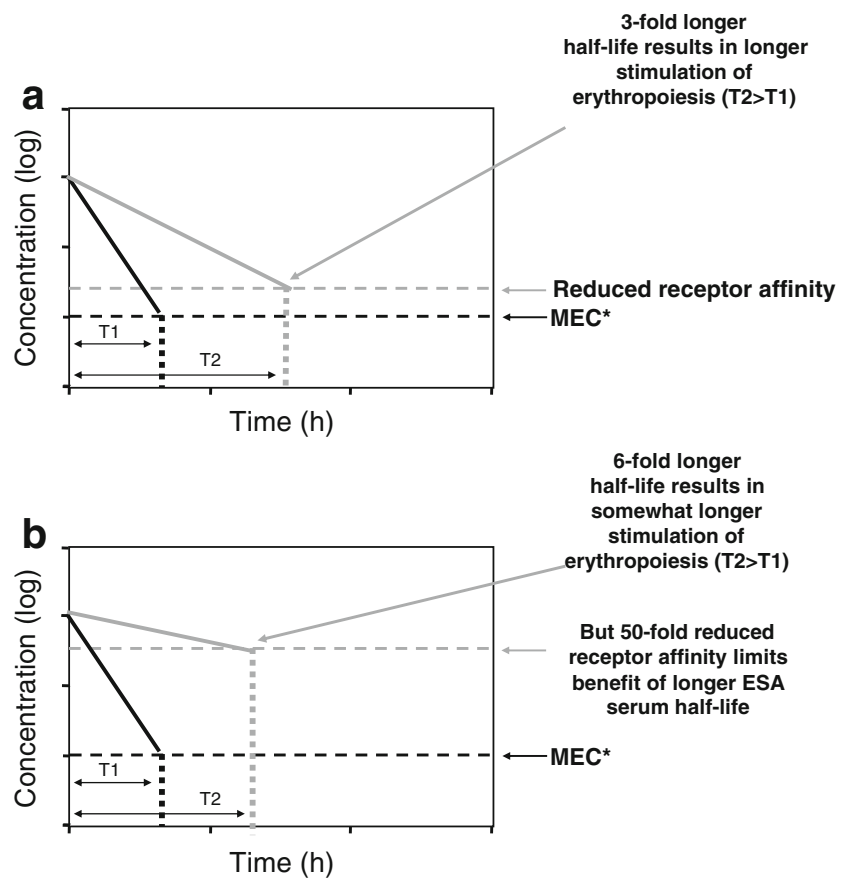

Fig. 7 a Model for darbepoetin alfa, which has decreased receptor affinity and longer half-life than recombinant human erythropoietin (rHuEPO). Longer serum half-life of darbepoetin alfa more than compensates for reduced affinity. b Dramatically reduced receptor affinity limits gain in biological activity due to longer half-life esis is stimulated. To reduce this possibility, lower starting doses may be used, and a longer period of time may elapse before a dose adjustment might be made. These issues limit the ability to implement a frequent dose titration if the patient or caregiver required it.

Binding of EPO to EPOR can result in either dissociation from its receptor, or the complex (EPO-EPOR) can be internalized into the cell where degradation occurs. Possibly, affinity to the receptor affected the likelihood that ESA would be bound and therefore the rate at which degradation could occur. Therefore, some have suggested that there is a causal relationship between slower clearance and reduced receptor affinity [2].

To determine whether differences in affinity to the EPO receptor translated into differences in clearance, intracellular trafficking of darbepoetin alfa and rHuEPO were assessed in vitro in an EPO-dependent cell line [59]. With rHuEPO, approximately $57 \%$ of bound material was internalized into the cell. Whereas $60 \%$ of EPO was recycled intact to the cell surface, $40 \%$ of the internalized material was degraded. This observation suggests that EPOR-mediated binding endocytosis and degradation could clear this agent. Whereas the reduced EPO receptor affinity of darbepoetin alfa did affect the likelihood of binding, the intracellular trafficking of rHuEPO and darbepoetin alfa were similar.

To determine whether EPOR-mediated degradation explained the reduced clearance of darbepoetin alfa in vivo, experiments with rHuEPO analogs with different receptor binding and clearance properties were performed [46]. Pharmacokinetic characteristics of an EPO analog (NM385), which had no detectable EPOR binding activity, showed only a modest difference in clearance compared with rHuEPO. In contrast, darbepoetin alfa and its polyethylene glycol-linked form had longer half-lives and reduced clearance compared with NM385. Assuming that NM385 with a complete block in Epo-receptor-mediated clearance represented the maximum effect of Epo-receptormediated clearance, and observing that darbepoetin alfa had a longer serum half-life than NM385, then the longer halflives of darbepoetin alfa and its polyethylene-glycol-linked form must be due to a reduction in clearance of pathways independent of the EPO receptor.

\section{Other ESAs}

As with darbepoetin alfa, other ESAs, such as pegylated forms of rHuEPO, biosimilars, or EPO mimetic peptides (Hematide), have the same mechanism of action as rHuEpo: binding and activation of EPOR [60]. However, they can be differentiated from each other according to differences in manufacturing methods, affinity to the EPO receptor, and 
serum half-life. As a result, in clinical practice, all these differences should be considered simultaneously. Mircera ${ }^{\circledR}$ (methoxy polyethylene glycol-epoetin beta) is epoetin beta with a covalent attachment to the peptide backbone of a linear methoxypolyethylene glycol (PEG), resulting in approximately a doubling in size compared with epoetin alfa (30.4 vs $60 \mathrm{kDa}$ ) [61]. PEG-epoetin beta has a prolonged elimination half-life in patients with $\mathrm{CKD}$, approximately $134 \mathrm{~h}$ [62]. Mircera ${ }^{\circledR}$ is approved to treat anemia associated with CKD in Europe. Hematide is a synthetic ESA comprised of nonnaturally occurring amino acids in a dipeptide that binds to the EPO receptor, thereby activating it $[63,64]$. The peptide was pegylated to increase serum half-life and is currently in clinical development.

\section{Conclusions}

In the past 20 years, our knowledge concerning erythropoietin and erythropoiesis has increased significantly. The first milestone was to introduce rHuEPO into clinical practice. This dramatically changed treatment options, increased energy levels of patients and reducing the incidence of transfusions. Whereas the biological function of rHuEPO is typically determined by the protein component, carbohydrate can play a role in molecular stability, solubility, in vivo activity, serum half-life, and immunogenicity. Darbepoetin alfa, an rHuEPO analog with two additional N-linked carbohydrate chains, was discovered and developed. Darbepoetin alfa has been used to successfully treat anemia in many patient populations, including those with chemotherapyinduced anemia and anemia associated with CKD. Darbepoetin alfa is cleared more slowly from the body and has a longer-lasting effect, resulting in a higher invivo-specific activity compared with rHuEPO. Darbepoetin alfa is indicated for an increased interval between administrations of the drug.

Acknowledgements The manuscript was sponsored by Amgen (Hungary). Vladimir Tesar participated in the advisory board for Amgen and Novartis; received a research grant from Amgen and lecture fees from Amgen, Astra Zeneca, Fresenius Kabi, Novartis, Roche and Teva. János Szegedi received consulting fees from Amgen and Janssen Cilag and participated in the advisory board for Amgen. Zoltán Kiss, Steven Elliott, Kinga Jedynasty are employees of Amgen.

\section{References}

1. Hebbel RP, Eaton JW (1989) Pathobiology of heme interaction with the erythrocyte membrane. Semin Hematol 26:136-149

2. Egrie JC, Browne JK (2001) Development and characterization of novel erythropoiesis stimulating protein (NESP). Nephrol Dial Transplant 16(Suppl 3):3-13
3. Elliott S, Heatherington AC, Foote M (2004) Cancer drug discovery and development hematopoietic growth factors in oncology: basic science and clinical therapeutics, 6 chapter, Erythropoietic factors-Clinical pharmacology and pharmacokinetics. Human Press Inc, Totowa, NJ, pp 97-123

4. Erslev A (1952) Humoral regulation of red cell production. Blood 8:349-357

5. Miyake T, King CK, Goldwasser E (1977) Purification of human erythropoietin. J Biol Chem 252:5558-5564

6. Lin FK, Suggs S, Lin CH, Browne JK, Smalling R, Egrie JC (1985) Cloning and expression of the human erythropoietin gene. Proc Natl Acad Sci USA 82:7580-7584

7. Lai PH, Everett R, Wang FF, Arakawa T, Goldwasser E (1986) Structural characterization of human erythropoietin. J Biol Chem 261:3116-3121

8. Syed RS, Reid SW, Li C et al (1998) Efficiency of signalling through cytokine receptors depends critically on receptor orientation. Nature 395:511-516

9. Jiang BH, Rue E, Wang GL, Roe R, Semenza GL (1996) Dimerization, DNA binding and transactivation properties of hypoxia-inducible factor 1 . J Biol Chem 271:17771-17778

10. Davis JM, Arakawa T, Strickland TW, Yphantis DA (1987) Characterization of recombinant human erythropoietin produced in Chinese hamster ovary cells. Biochemistry 26:2633-2638

11. Elliott S, Lorenzini T, Chang D, Barzilay J, Delorme E (1997) Mapping of active site of recombinant human erythropoietin. Blood 89:493-502

12. Watowich SS (1999) Activation of erythropoietin signaling by receptor dimerization. Int J Biochem Cell Biol 31:1075-1088

13. Alfrey CP, Fishbane S (2007) Implications of neocytolysis for optimal management of anaemia in chronic kidney disease. Nephron Clin Pract 106:c149-c156

14. Sinclair A, Coxon A, McCaffery I et al (2010) Functional erythropoietin receptor is undetectable in endothelial, cardiac, neuronal and renal cells. Blood, In press

15. Landaw SA, Leon HA, Winchell HS (1970) Effects of hyperoxia on red blood cell survival in the normal rat. Aerosp Med 41(1):48-55

16. Fisher CL, Johson PC, Berry CA (1967) Red blood cell mass and plasma volume changes in manned space flight. JAMA 200 (7):579-583

17. Berry CA (1969) Preliminary clinical report of the medical aspects of Apollos VII and VIII. Aeros Med 40:245-254

18. Hattangadi SM, Lodish HF (2007) Regulation of erythrocyte lifespan: do reactive oxygen species set the clock? J Clin Invest 117:2075-2077

19. Marinkovic D, Zhang X, Yalcin S, Luciano JP, Brugnara C, Huber T, Ghaffari S (2007) Foxo3 is required for the regulation of oxidative stress in erythropoiesis. J Clin Invest 117:2133-2144

20. Wu H, Lee SH, Gao J, Liu X, Iruela-Arispe ML (1999) Inactivation of erythropoietin leads to defects in cardiac morphogenesis. Development 126(16):3597-3605

21. Erbayraktar S, Yilmaz O, Gokmen N, Brines M (2003) Erythropoietin is a multifunctional tissue-protective cytokine. Current Hematology Reports 2(6):465-470

22. Logar CM, Brinkkoetter PT, Krofft RD, Pippin JW, Shankland SJ (2007) Darbepoetin alfa protects podocytes from apoptosis in vitro and in vivo. Kidney Int 72(4):489-498

23. Eto $N$, Wada $T$, Inagi $R$, Takano $H$, Shimizu A, Kato H, Kurihara H, Kawachi H, Shankland SJ, Fujita T, Nangaku M (2007) Podocyte protection by darbepoetin: preservation of the cytoskeleton and nephrin expression. Kidney Int 72(4):455-463

24. Jelkmann W, Bohlius J, Hallek M, Sytkowskí AJ (2008) The erythropoietin receptor in normal and cancer tissue. Crit Rev Oncol Hematol 67:39-61

25. Sinclair AM, Todd MD, Forsythe K et al (2007) Expression and function of erythropoietin receptors in tumors: implications for the 
use of erythropoiesis-stimulating agents in cancer patients. Cancer 110:477-488

26. Glaspy JA (2008) Erythropoiesis-stimulating agents in oncology. J Natl Compr Canc Netw 6:565-575

27. Brown WM, Maxwell P, Graham AN, Yakkundi A, Dunlop EA, Shi Z, Johnston PG, Lappin TR (2007) Erythropoietin receptor expression in non-small cell lung carcinoma: a question of antibody specificity. Stem Cells 25(3):718-722

28. Elliott S, Busse L, Bass MB, Lu H et al (2006) Anti-Epo receptor antibodies do not predict Epo receptor expression. Blood 107:1892-1895

29. Suzuki N, Ohneda O, Takahashi S, Higuchi M, Mukai HY, Nakahata T, Imagawa S, Yamamoto M (2002) Erythroid-specific expression of the erythropoietin receptor rescued its null mutant mice from lethality. Blood 100(7):2279-2288

30. Laugsch M, Metzen E, Svensson T, Depping R, Jelkmann W (2008) Lack of functional erythropoietin receptors of cancer cell lines. Int J Cancer 122:1005-1011

31. Elliott S, Busse L, McCaffery I et al (2009) Identification of sensitive anti-erythropoietin receptor monoclonal antibody allows detection of low levels of EpoR in cells. J Immunol Methods. doi: 10.1016/j.jim.2009.10.006

32. Swift S, Elliott S, Sinclair A, Begley CG (2009) Erythropoietin receptor in ovarian cancer cells. Mol Cancer Ther

33. Rossi J, McCaffery I, Paweletz K et al (2009) Analysis of cell surface erythropoietin receptor (EpoR) expression and function in human epithelial tumor tissues. J Clin Oncol 27:abstr 11104

34. Katavetin P, Tungsanga K, Eiam-Ong S, Nangaku M (2007) Antioxidative effects of erythropoietin. Kidney Int Suppl 107: S10-S15

35. Schellekens Huub (2009) Biosimilar therapeutics-what do we need to consider? Nephrol Dial Transplant Plus 2(Suppl 1):i27-i36

36. Schellekens H (2005) Follow-on biologics: Challenges of the 'next generation'. Nephrol Dial Transplant 20:iv31-iv36

37. Jelkmann W (2009) Efficacy of recombinant erythropoietins: is there unity of international units? Nephrol Dial Transplant 24:1366-1368

38. Park SS, Park J, Ko J et al (2009) Biochemical assessment of erythropoietin products from Asia versus US Epoetin alfa manufactured by Amgen. J Pharm Sci 98:1688-1699

39. Elliott S, Egrie J, Browne J, Lorenzini T, Busse L, Rogers N, Ponting I (2004) Control of rHuEPO biological activity: The role of carbohydrate. Exp Hematol 32:1146-1155

40. Strickland T, Adler B, Aoki K, Asher S, Derby P, Goldwasser E, Rogers G (1992) Occurrence of sulfate on the N-linked oligosaccharides of human erythropoietin. J Cell Biochem Supplement 16D:167, Ref Type: Abstract

41. Lasne F, Martin L et al (2002) Detection of isoelectric profiles of erythropoietin in urine: Differentiation of natural and administered recombinant hormones. Anal Biochem 311:119-12

42. Egrie JC, Browne JK (2001) Development and characterization of novel erythropoiesis stimulating protein (NESP). Br J Cancer 84 (Suppl 1):3-10

43. Elliott S, Chang D, Delorme E, Eris T, Lorenzini T (2004) Structural requirements for additional $\mathrm{N}$-linked carbohydrate on recombinant human erythropoietin. J Biol Chem 279:16854-16862

44. Delorme E, Lorenzini T, Giffin J et al (1992) Role of glycosylation on the secretion and biological activity of erythropoietin. Biochemistry 31:9871-9876

45. Elliott S, Lorenzini T, Asher S, Aoki K, Brankow D, Buck L, Busse L et al (2003) Enhancement of therapeutic protein in vivo activities glycoengineering. Nature 21:414-421

46. Agoram B, Aoki K, Doshi S, Gegg Co, Jang G, Molineux G, Narhi L, Elliott S (2009) Investigation of the Effects of Altered Receptor Binding Activity on the Clearance of ErythropoiesisStimulating Proteins: Nonerythropoietin Receptor-Mediated Pathways May Play a Major Role. J Pharm Sci 98(6):2198-2211
47. Egrie JC, Dwyer E, Browne JK, Hitz A, Lykos MA (2003) Darbepoetin alfa has a longer circulating half-life and greater in vivo potency than recombinant human erythropoietin. Exp Hematol 31:290-299

48. Macdougall IC, Gray SJ, Elston O et al (1999) Pharmacokinetics of novel erythropoiesis stimulating protein compared with epoetin alfa in dialysis patients. J Am Soc Nephrol 10:2392-2395

49. Glaspy J, Henry D, Patel R et al (2005) Effects of chemotherapy on endogenous erythropoietin levels and the pharmacokinetics and erythropoietic response of darbepoetin alfa: a randomised clinical trial of synchronous versus asynchronous dosing of darbepoetin alfa. Eur J Cancer 41:1140-1149

50. Allon M, Kleinman K, Walczyk M, Kaupke C, Messer-Mann L, Olson K, Heatherington AC, Maroni BJ (2002) Pharmacokinetics and pharmacodynamics of darbepoetin alfa and epoetin in patients undergoing dialysis. Clin Pharmacol Ther 72:546-555

51. Macdoughall IC (2002) Optimizing the use of erythropoietic agents-pharmacokinetic and pharmacodynamic considerations. Nephrol Dial Transplant 17(Suppl 5):66-70

52. Mann J, Kessler M, Villa G (2007) Darbepoetin alfa once every 2 weeks for treatment of anemia in dialysis patients: a combined analysis of eight multicenter trials. Clin Nephrol 67:140-148

53. Sinclair AM, Elliott S (2005) Glycoengineering: the effect of glycosylation on the properties of therapeutic proteins. J Pharm Sci 94:1626-1635

54. Hartley C, Eliott S, Begley G, McElroy P, Sutherland W, Khaja R, Heatherington AC, Graves T, Schultz H, Castilio JD, Molineux G (2003) Kinetics of haematopoietic recovery after dose-intensive chemo/radiotherapy in mice: Optimized erythroid support with darbepoetin alpha. Br J Haematol 122:623-636

55. Sasu BJ, Hartley C, Schultz H et al (2005) Comparison of epoetin alfa and darbepoetin alfa biological activity under different administration schedules in normal mice. Acta Haematol 113:163-174

56. Tolman C, Richardson D, Bartlett C, Will E (2005) Structured conversion from thrice weekly to weekly erythropoietic regimens using a computerized decision-support system: a randomized clinical study. J Am Soc Nephrol 16:1463-1470

57. Carrera F, Oliveira L (2006) The efficacy of intravenous darbepoetin alfa administered once every 2 weeks in chronic kidney disease patients on hemodialysis. Nephrol Dial Transplant 21:2846-2850

58. Ling B, Walczyk M (2005) Darbepoetin alfa administered once monthly maintains haemoglobin concentration in patients with chronic kidney disease. Clin Nephrol 63:327-334

59. Gross AW, Lodish HF (2006) Cellular trafficking and degradation of erythropoietin and novel erythropoiesis stimulating protein (NESP). J Biol Chem 281:2024-2032

60. Eliott S, Pham E, Macdougall IC (2008) Erythropoiesis: a common mechanism of action. Exp Hematol 36:1573-1584

61. Jarsch M, Brandt M, Lanzendorfer M, Haselbeck A (2008) Comparative erythropoietin receptor binding kinetics of C.E.R. A. and epoetin-beta determined by surface plasmon resonance and competition binding assay. Pharmacology 81:63-69

62. Macdougall IC et al. (2006) Pharmacokinetics and pharmacodynamics of intravenous and subcutaneous continuous erythropoietin receptor activator (C.E.R.A.) in patients with chronic kidney disease. Clin J Am Soc Nephrol 1:1211-1215

63. Fan Q, Leuther KK et al (2006) Preclinical evaluation of Hematide, a novel erythropoiesis stimulating agent, for the treatment of anemia. Exp Hematol 34:1303-1311

64. Stead RB, Lambert J, Wessels D et al (2006) Evaluation of the safety and pharmacodynamics of Hematide, a novel erythropoietic agent, in a phase 1, double-blind, placebo-controlled, dose-escalation study in healthy volunteers. Blood 108:1830 1834 